\title{
The genetics of congenital central hypoventilation syndrome: clinical implications
}

This article was published in the following Dove Press journal:

The Application of Clinical Genetics

\author{
John Bishara' \\ Thomas G Keens ${ }^{1,2}$ \\ Iris A Perez ${ }^{1,2}$ \\ 'Division of Pediatric Pulmonology \\ and Sleep Medicine, Children's \\ Hospital Los Angeles, Los Angeles, \\ CA, USA; ${ }^{2}$ Department of Pediatrics, \\ Keck School of Medicine of USC, Los \\ Angeles, CA, USA
}

\begin{abstract}
Congenital central hypoventilation syndrome (CCHS) is a rare genetic disorder of the autonomic nervous system (ANS) and respiratory control. This disorder, formerly referred to as Ondine's curse, is due to a mutation in the $P H O X 2 B$ gene that affects the development of the neural crest cells. CCHS has an autosomal dominant pattern of inheritance. Majority of the patients have a polyalanine repeat mutation (PARM) of the $P H O X 2 B$, while a small group has non-PARM (NPARM). Knowledge of the patient's $P H O X 2 B$ gene mutation helps predict a patient's clinical presentation and outcome and aids in anticipatory management of the respiratory and ANS dysfunction.
\end{abstract}

Keywords: diaphragm pacing, noninvasive positive pressure ventilation, genetic counseling, genetic testing, CCHS, PHOX2B, congenital central hypoventilation syndrome

\section{Introduction}

Congenital central hypoventilation syndrome (CCHS) is a rare genetic disorder of the autonomic nervous system (ANS) and respiratory control due to a mutation in the paired-like homeobox 2B (PHOX2B) gene found on chromosome $4 .{ }^{1}$ CCHS patients usually present in the newborn period with apnea, hypoxemia, and hypoventilation that are most severe during sleep, particularly during nonrapid eye movement (NREM) sleep..$^{1-5}$ Over 1,000 cases have been reported worldwide and are expected to be higher due to the availability of genetic testing. The estimated incidence is one in 150,000-200,000 live births in France and Japan. ${ }^{6,7}$ In 2003, the PHOX2B gene was identified as the disease-defining gene for CCHS and has prompted clinical genetic testing, making the diagnosis exact and early treatment feasible. ${ }^{8,9}$ In this review, we discuss the clinical presentation, genetics of CCHS, and how the genotype affects the presentation, management, and outcome of CCHS patients.

\section{Clinical presentation}

Most CCHS patients present in the neonatal period with apnea or hypercapnia requiring assisted ventilation. ${ }^{1,5,6,10}$ Typically, these newborns will present with central apneas and cyanosis resulting in the need for assisted ventilation either invasively or noninvasively. ${ }^{1,4-7}$ The hypoventilation is significantly worse during sleep, particularly during quiet, NREM sleep where breathing is critically dependent on the metabolic/ automatic control of breathing. ${ }^{2,3}$ However, hypoventilation may persist during active, rapid eye movement sleep and into wakefulness, albeit usually to a milder degree. ${ }^{1-3}$ These infants do not increase their respiratory rate or tidal breathing and do not mani-
Division of Pediatric Pulmonology and Sleep Medicine, Children's Hospital of Los Angeles, 4650 Sunset Boulevard, Los Angeles, CA 90027, USA

$\mathrm{Tel}+|32336| 210 \mid$

$\mathrm{Fax}+|32336| 1355$

Email iaperez@chla.usc.edu 
fest respiratory distress, despite significant hypercapnia and hypoxemia. Once placed on ventilatory support, they fail to be weaned off assisted ventilation. As they mature, some infants may develop a normal pattern of adequate breathing while awake, allowing them to be off assisted ventilation for periods of time during wakefulness. ${ }^{1,2,4,6,11-14}$

Children and adults may present with unexplained apneas, significant hypoventilation without significant changes in their breathing pattern, or respiratory failure following either respiratory infection ${ }^{15-18}$ or after undergoing sedation/ anesthesia. ${ }^{19-22}$ They have inadequate ventilatory responses to both hypercapnia and hypoxemia ${ }^{23}$ and do not experience discomfort or dyspnea in response to either hypercapnia or hypoxia. ${ }^{24}$ Therefore, they do not exhibit signs of respiratory distress in spite of significant hypoventilation. Furthermore, it is not unusual for some patients to report unusual ability to voluntarily hold their breaths for long periods as well as extraordinary capabilities for underwater swimming. ${ }^{21}$ Some may present with seizures due to undetected hypoxemia and/ or hypercapnia. ${ }^{21,22,25}$ In light of unrecognized chronic respiratory failure, some patients may present with associated polycythemia. ${ }^{21,26,27}$ Others may exhibit diaphoresis, edema, and signs of right heart failure leading to a mistaken diagnosis of congenital heart disease. In older children and adults, pulmonary hypertension and cor pulmonale are the results from unrecognized and untreated hypoxemia and hypoventilation and may be the presenting signs. ${ }^{17,21,28,29}$

CCHS is not just a disorder of respiratory control. Affected patients may have associated conditions due to ANS dysfunction including tumors of neural crest origin (neuroblastoma, ganglioneuroma, and ganglioneuroblastoma $)^{6,30-32}$ gastrointestinal manifestations such as esophageal dysmotility, ${ }^{14,33}$ constipation, ${ }^{14}$ aganglionic megacolon Hirschsprung's disease (HSCR), ${ }^{1,6,14,34}$ and other signs and symptoms attributed to abnormal development of neural crest cells such as cardiovascular, ${ }^{25,35-39}$ ophthalmologic, ${ }^{14,40-43}$ endocrinologic, ${ }^{44-48}$ and temperature regulation abnormalities. ${ }^{49} \mathrm{CCHS}$ patients may have dizziness and syncopal episodes due to cardiac rhythm or blood pressure control abnormalities. Hyperinsulinism and hypoglycemia may also predispose to seizures. ${ }^{48}$ A summary of clinical manifestations of CCHS are listed in Table 1.1,50

\section{PHOX2B gene mutation}

$\mathrm{CCHS}$ is caused by a defect in the $P H O X 2 B$ gene that is located in chromosome $4 \mathrm{p} 12 .{ }^{1,8,9} \mathrm{PHOX} 2 \mathrm{~B}$ is a protein comprised 314 amino acids with two short and stable polyalanine repeats of 9 and 20 residues in the $\mathrm{C}$ terminus. It encodes a highly conserved homeodomain transcription factor that
Table I Clinical manifestations of CCHS

\begin{tabular}{|c|c|}
\hline Organ System & Clinical manifestations \\
\hline \multirow[t]{5}{*}{ Ophthalmologic } & Decreased/absent pupillary light response \\
\hline & Anisocoria \\
\hline & Strabismus \\
\hline & Lack of convergent gaze \\
\hline & Marcus Gunn jaw winking \\
\hline \multirow[t]{2}{*}{ Respiratory } & Alveolar hypoventilation \\
\hline & Absent perception of dyspnea \\
\hline \multirow[t]{9}{*}{ Cardiovascular } & Bradycardia \\
\hline & Prolonged sinus pauses ( $>3$ seconds) \\
\hline & Transient asystole \\
\hline & Decreased heart rate variability \\
\hline & Low normal daytime blood pressure \\
\hline & Orthostatic hypotension \\
\hline & Nondipping blood pressure circadian pattern \\
\hline & Decreased BP response to exercise \\
\hline & Syncope \\
\hline \multirow[t]{3}{*}{$\mathrm{Gl}$} & Hirschsprung's disease (20\%) \\
\hline & Constipation \\
\hline & Esophageal dysmotility \\
\hline \multirow[t]{3}{*}{ Endocrine } & Hyperinsulinism \\
\hline & Hypoglycemia \\
\hline & Hyperglycemia \\
\hline \multirow[t]{4}{*}{ Neuro } & Decreased anxiety \\
\hline & Decreased pain perception \\
\hline & Seizures \\
\hline & Neurocognitive deficits \\
\hline Skin & Sporadic profuse sweating \\
\hline \multirow[t]{3}{*}{ Tumors } & Neuroblastoma \\
\hline & Ganglioneuroma \\
\hline & Ganglioneuroblastoma \\
\hline \multirow[t]{2}{*}{ Others } & Decreased baseline body temperature \\
\hline & Poor heat tolerance \\
\hline
\end{tabular}

Abbreviations: $\mathrm{CCHS}$, congenital central hypoventilation syndrome; BP, blood pressure; $\mathrm{Gl}$, gastrointestinal.

is essential in the development of the respiratory control neurons and ANS. ${ }^{51,52}$ Majority (90\%) of CCHS patients are heterozygous for an in-frame triplet duplication within the sequence stretch coding for 20 alanine amino acids in exon 3 , resulting in polyalanine repeat mutations (PARMs) having an additional 4-13 alanine residues. Thus, the normal 20-alanine tract is expanded to 24-33 alanine repeats, with resultant genotypes of 20/24-20/33 PARMs. ${ }^{1}$ The normal PHOX2B gene has 20 alanine repeats (20/20 genotype). The most common genotypes in CCHS are 20/25, 20/26, and 20/27 PARMs. ${ }^{1}$ Ten percent of CCHS patients are heterozygous for non-PARMs (NPARMs) in exon 1, 2, or 3. These mutations include missense, nonsense, frame shift, and stop codon mutations. Most of the NPARMs are located in exon 2 and exon $3 .^{1}$ The $P H O X 2 B$ exon or whole gene deletion accounts for $<1 \%$ of cases and is associated with variable phenotypes. ${ }^{31}$ 


\section{PHOX2B and respiratory control}

A series of physiologic studies suggest that the abnormality in CCHS is located in the area of the brainstem involved in the integration of both central and peripheral chemoreceptor inputs. The central chemoreceptors are found in the midline raphe, retrotrapezoid nucleus (RTN), ventrolateral quadrant of the medulla, nucleus tractus solitarius (NTS), and the locus ceruleus (LC). The central chemoreceptors sense changes in $\mathrm{pH}$ and $P_{\mathrm{CO}_{2}}$. The peripheral chemoreceptors are located in the aortic and carotid bodies and sense changes in Po2, as well as to a lesser degree $\mathrm{pH}$ and $P_{\mathrm{CO}_{2}}$. The chemoreceptors send inputs to the ventilatory controllers (central pattern generator) in the pons and medulla that then relay commands to the ventilatory muscles to perform breathing. Paton et $\mathrm{al}^{23}$ showed that children with CCHS have absent ventilatory responses to both hypercapnia and hypoxia even while awake, suggesting abnormal central and peripheral chemoreceptor function or abnormality in the brainstem integration of chemoreceptor inputs. Marcus et $\mathrm{al}^{53}$ tested the hypoxic and hypercapnic arousal responses of CCHS children and showed that under very controlled conditions, most CCHS patients have arousal responses, although blunted, to hypercapnia, thus demonstrating intact central chemoreceptor input. Gozal et $\mathrm{al}^{54}$ then tested the ventilatory responses to acute hypoxia, hyperoxia, and hypercapnia in CCHS children who were able to sustain adequate ventilation during wakefulness and found that CCHS patients have ventilatory depression with hyperoxia while awake, thus showing that peripheral chemoreceptor function was also present and intact. Taken together, these studies point to a primary physiologic abnormality in the integration of chemoreceptor inputs rather than abnormalities in the chemoreceptors themselves.

$P H O X 2 B$ is present throughout the peripheral and central nervous systems. $P H O X 2 B$ is expressed by a chain of neurons involved in cardiovascular, respiratory, and digestive control and persists in most brainstem structures after birth including the hypercapnia-sensitive neurons of the RTN and the neurons of the nucleus of the solitary tract that mediate peripheral chemoreceptor function..$^{51,52,55-57}$ Studies support the key role of brainstem RTN in the control of breathing. RTN neurons are thought to function as central chemoreceptors regulating alveolar ventilation as well as site of integration of excitatory inputs from the peripheral chemoreceptors, raphe, and hypothalamus as well as from neighboring astrocytes that modulate respiratory drive. ${ }^{58,59}$ In mice, phox $2 b$ function is fundamental to the development of the RTN ${ }^{60}$ Mice with phox $2 b$ mutation causing the severe form of CCHS are born without RTN neurons and die at birth from respira- tory failure. ${ }^{61}$ These mouse models of CCHS with phox $2 b$ mutations indicate how the lack of $P H O X 2 B$ expression and RTN neuron agenesis are vital in the control of breathing and autonomic regulation..$^{58}$ Although an RTN-like structure has been identified in humans, there is currently no evidence that this is lacking in CCHS patients. ${ }^{62}$

$P h o x 2 b$ is required in the differentiation of all noradrenergic centers in the brain, including the LC.$^{63}$ The LC fails to form in homozygous phox $2 \mathrm{~b}$-deficient mice. ${ }^{63}$ Nobuta et al ${ }^{64}$ found neuronal losses within the LC in two lethal neonatal postmortem cases with a confirmed $P H O X 2 B$ PARM or NPARM mutation. Mouse models also showed failure of the LC development and perinatal respiratory lethality, indicating that LC neuronal development is hindered with early onset mutant PHOX2B expression in CCHS. ${ }^{64}$ Phox $2 \mathrm{~B}$ is likewise expressed in the NTS that conveys excitatory input from the carotid bodies (whose development are also controlled by phox $2 b$ ) to the RTN. ${ }^{55,57,58}$ Tomycz et al ${ }^{65}$ reported novel brain findings in a full term infant with Haddad syndrome who died at 27 days of life with hypoplasia of the LC, delayed maturation of the arcuate nucleus (a putative homolog of the ventral medullary neurons in animals), and aberrant fascicles in the NTS. These abnormalities suggest that CCHS occurs in a network of sites critical to chemoreception. ${ }^{65}$ Using functional MRI, Ogren et a ${ }^{166}$ found muted and time-lagged responses to Valsalva maneuver in CCHS patients compared to controls, suggesting that the autonomic disturbances in CCHS most likely result from an impaired network of brain structures mediating sympathetic and parasympathetic control and not just alterations to isolated brainstem nuclei.

\section{Diagnosis and evaluation}

All patients suspected of CCHS must be confirmed with the PHOX2B gene mutation analyses. ${ }^{1}$ There are three PHOX2B testing methods currently available in establishing the diagnosis: 1) PHOX2B targeted mutation analysis (PHOX2B screening test; fragment length analysis), ${ }^{1,67}$ 2) PHOX2B sequencing test, ${ }^{1,67}$ and 3) deletion/duplication analysis. ${ }^{31}$ PHOX2B-targeted mutation analysis involves PCR amplification of the 20 repeat polyalanine expansion region of exon 3 and determines the polyalanine repeat length. It identifies all PARMS and most NPARMs (large deletions and some out of frame deletions or duplications). These tests identify pathogenic variants in $\sim 95 \%$ of individuals with CCHS. The PHOX2B-targeted mutation analysis has a very low limit of detection of mosaicism (1\%). ${ }^{68}$ Thus, it is considered the most appropriate test in the identification of low level mosaicism for both PARM and NPARM, ${ }^{1,67-69}$ in seemingly asymptomatic 
and mildly symptomatic individuals. The PHOX2B sequencing test identifies all PARMs and all known NPARMs. However, PHOX2B sequencing test has a limit of detection of $20 \%{ }^{68}$ and, thus, may not detect low-level mosaicism. ${ }^{68,69} P H O X 2 B$ deletion/duplication testing identifies deletions of exon 3 or of the whole $P H O X 2 B$ with other nearby genes; variants could be missed in the screening or sequencing tests. ${ }^{31,67}$ Testing methods may include quantitative PCR, long-range PCR, multiplex ligation-dependent probe amplification, and chromosomal microarray that includes this gene/chromosome. ${ }^{67}$ Deletion/ duplication analysis may identify $<1 \%$ of patients with CCHS. ${ }^{31,67}$ When clinical suspicion is high, a combination of the screening, sequencing test, and deletion/duplication analysis may be required in cases in which one test fails to identify the disease-causing mutation. ${ }^{67}$ Regardless of the method of testing used, patient and parents should undergo genetic counseling. While awaiting the $P H O X 2 B$ gene testing results, an evaluation to rule out primary pulmonary, cardiac, neurologic, neuromuscular, and metabolic causes of hypoventilation may be undertaken. Suggested tests are listed in Table $2 .^{1}$

Once a diagnosis is established, CCHS patients with symptoms or those at risk (depending on genotype) should be screened for associated autonomic dysfunction. ${ }^{1}$ Tests to consider include 1) barium enema or rectal biopsy to assess HSCR, 2) cardiac rhythm monitoring to evaluate arrhythmias, and 3 ) chest and abdominal imaging to assess neural crest tumors. ${ }^{1}$ Traditionally, 72-hour Holter monitoring has been used in the assessment of cardiac rhythm disturbances, but recent advent of the Zio patch monitoring that allows longer evaluation ${ }^{70,71}$ has been used at our center. Patients should be referred for comprehensive ophthalmology evaluation to identify abnormalities and provide intervention to prevent

Table 2 Suggested tests to assess other causes of hypoventilation

\begin{tabular}{|c|c|}
\hline Systems & Test \\
\hline \multirow[t]{4}{*}{ Respiratory } & Chest X-ray \\
\hline & CT chest \\
\hline & Pulmonary function test \\
\hline & Fluoroscopy or ultrasound of the diaphragm \\
\hline \multirow[t]{2}{*}{ Cardiologic } & Echocardiogram \\
\hline & EKG \\
\hline Neurologic & Brain MRI \\
\hline Inborn errors & Metabolic screening \\
\hline of metabolism/ & Muscle biopsy \\
\hline mitochondrial disease & \\
\hline
\end{tabular}

Abbreviations: CT, computed tomography; EKG, Electrocardiography. learning interference. ${ }^{1,11,12} \mathrm{CCHS}$ patients have been found to demonstrate developmental delay and neurocognitive deficits as early as preschool age indicating need for neurocognitive evaluation. ${ }^{14,72-76}$

\section{Genotype-phenotype relationship}

The $P H O X 2 B$ gene mutation not only confirms the diagnosis of CCHS but also aids in predicting the respiratory compromise and associated ANS dysfunction.

\section{Alveolar hypoventilation}

Alveolar hypoventilation is the hallmark of CCHS. The severity of respiratory failure and the need for ventilatory support can be anticipated by a patient's genotype. ${ }^{1}$ In general, those with shorter PARMS (20/24-20/25) have more subtle symptoms and later onset with some surviving to adulthood without the need for ventilatory assistance. ${ }^{21}$ They usually require assisted ventilation only during sleep. Some are asymptomatic until there is an associated triggering event (ie, exposure to respiratory illness, sedation, or anesthesia) that puts them in respiratory compromise. These clinical presentations indicate incomplete penetrance and variable expressivity for 20/24 and 20/25 PARMs. In these shortsized PARMs, the cellular defects are found to be relatively milder and may not always reach the threshold for clinical disease (presymptomatic) or may have a mild phenotypic consequence. ${ }^{21}$ However, the presence of genetic modifiers or environmental cofactors acting in conjunction with $\mathrm{PHOX} 2 \mathrm{~B}$ impairment may allow the symptoms to manifest. ${ }^{21,22}$

CCHS patients with larger PARMs typically present in the newborn period. Those with 20/26 PARMs generally require ventilatory support during sleep and possibly during wakefulness depending on activity. CCHS patients with 20/27-20/33 PARMs are typically symptomatic at birth and require full-time ventilatory support. ${ }^{1}$ With maturation of the respiratory system, some of these patients have been able to breathe adequately off the ventilator while awake and require ventilatory support only during sleep. ${ }^{77}$ This improvement indicates normal maturation of the respiratory system and not a change in the basic disorder. Larger PARMs are generally not associated with variable penetrance or adult onset presentations since increasing the PARMs has been found to have more severe cellular impairments. ${ }^{78-82}$

NPARM $P H O X 2 B$ genotype is also generally associated with more severe phenotype with patients typically requiring full-time ventilatory support. ${ }^{1}$ However, NPARM mutations have variable expressivity and incomplete penetrance. ${ }^{13,83,84}$ Some patients have been shown to present with 
central apneas without hypoventilation, ${ }^{85}$ mild hypoxemia, ${ }^{85}$ or need for assisted ventilation only during sleep ${ }^{13,84}$ while others are asymptomatic and are identified only by genetic testing through an affected family member. ${ }^{13,83,85}$ Cain et $\mathrm{al}^{84}$ described two patients with nonsense pathogenic variant in exon 1 of the PHOX2B producing an $\mathrm{N}$ terminally truncated protein presenting with milder phenotype (need for ventilatory support only during sleep and without HSCR or peripheral neuroblastic tumors). Lombardo et al reported a family with novel heterozygous mutation, c. $234 \mathrm{C}>\mathrm{G}$, and variable phenotype. Two siblings had sleep hypoxemia, anisocoria, HSCR, and characteristic facial features (one sibling did also have a congenital heart disease), while their mother had sleep apnea, anisocoria, and a congenital heart disease but without HSCR or malignancy. ${ }^{85}$ In 2017 , Kasi et a ${ }^{13}$ reported a threegeneration family with four individuals possessing a novel PHOX2B NPARM (c. $245 \mathrm{C}>\mathrm{T}$ ) with variable phenotypes. Two of the family members were ventilator dependent only during sleep, with one of them requiring a cardiac pacemaker. One of the adult family members was noted to have elevated $\mathrm{HCO}_{3}$ on routine blood testing and reports the history of extraordinary ability to hold her breath as a child. The other adult family member was asymptomatic. This report confirms previously reported variable expression of NPARM even within families. ${ }^{9}$ More recently, Di Lascio et al conducted a comprehensive review of all the frame shift mutations in CCHS reported in the literature and in their own cohort. They found that all the patients with frame 3 mutations (resulting from the insertion of two or more triplets + two nucleotides and the deletion of one or more triplets + one nucleotide) were present with isolated CCHS. In contrast, frame 2 mutations (resulting from the insertion of one or more triplets + one nucleotide and the deletion of two or more triplets + two nucleotides) were seen in the majority of syndromic CCHS. ${ }^{86}$

\section{Autonomic dysfunction}

ANS dysfunction has also been found to correlate with PHOX2B gene mutations.

\section{HSCR}

HSCR is reported to occur in about $20 \%$ of CCHS patients. It is most prevalent in patients with NPARM mutations ${ }^{1,87}$ and, to a lesser degree, patients with PARM 20/27. However, there is a report of patients with PARM 20/24 genotype with severe CCHS phenotype and HSCR.$^{88} \mathrm{HSCR}$ typically presents in the neonatal period. Males and females are equally affected and most frequently with the long colonic segment involvement. ${ }^{6}$ Di Lascio et al ${ }^{86}$ also found that all the syndromic phenotypes associated with frame 3 mutations included HSCR; syndromic CCHS was more frequently accompanied by HSCR than by neuroblastoma.

\section{Sinus pauses}

CCHS children with 20/27 PARM and, to a lesser extent, 20/26 PARM, are at risk for life-threatening sinus pauses of $>3$ seconds requiring cardiac pacemaker placement. ${ }^{1,37}$ In one series, children with $P H O X 2 B$ 20/25 PARM did not manifest sinus pauses of $>3$ seconds. ${ }^{37}$ However, there is a report of a 22-year-old adult with $P H O X 2 B$ 20/25 PARM with sinus pauses of up to 8.4 seconds during wakefulness occurring during a minor respiratory tract infection. ${ }^{21}$ We also recently reported a patient with NPARM who at 21 years developed bradycardia during sleep, in addition to palpitations and dizziness with exercise. ${ }^{13}$ Bradycardia and sinus pauses were documented on Holter monitoring, and the patient subsequently had cardiac pacemaker implantation. ${ }^{13}$ These findings indicate that CCHS patients with 20/25 PARM and NPARMs require monitoring for arrhythmias as they become older.

\section{Tumors of neural crest origin}

The overall risk of developing tumors of neural crest origin is $<2 \%$, with the risk higher in those with NPARMs and longer PARM (20/28-20/33) genotypes. ${ }^{1,86,87,89}$ In one series, neuroblastoma was found more in those with frame shift and missense PHOX2B mutations, suggesting that both mutations may predispose to neuroblastoma, as opposed to PARM. ${ }^{32}$ Furthermore, those with frame 2 mutations may be at increased predisposition to develop neuroblastoma tumors of sympathetic nervous system. ${ }^{86}$

\section{Ophthalmologic}

Patwari et $\mathrm{al}^{42}$ demonstrated that pupillary abnormalities were more frequent in patients with 20/26 and 20/27 PARMs than those with 20/25 PARM. A recent study revealed the presence of strabismus, pupillary, and iris abnormalities in CCHS adults. ${ }^{43}$ In this cohort, the prevalence of pupillary and iris abnormalities was less compared to children, indicating their potential role as systemic disease severity marker. ${ }^{43}$

\section{Neurocognitive}

Sub-optimal school performance and/or neurodevelopmental impairment have been reported in CCHS patients, ${ }^{72-76}$ and these deficits have recently been reported to appear as early as preschool age and school age. ${ }^{72,73}$ In a recent study, Bayley scores were essentially normal in patients with 20/25 PARM and lower in the other PARM groups. ${ }^{73}$ Furthermore, the 
study revealed that CCHS phenotype severity as indicated by cyanotic breath holding spells, need for 24-hour ventilator dependence, prolonged sinus pauses and seizures was associated with the severity of the neurocognitive delay. ${ }^{73}$

\section{Management}

The goal of treatment is to ensure adequate ventilation at all times, both while awake and during sleep to prevent morbidities secondary to untreated hypoxemia or hypercapnia and anticipatory management of associated autonomic dysfunction. ${ }^{1,4,11,12}$ At our center, we recommend maintaining $\mathrm{PetCO}_{2} \sim 35 \mathrm{mmHg}$ and $\mathrm{SpO}_{2} \geq 95 \%$. ${ }^{11,12}$ It is essential to recognize that oxygen alone relieves the hypoxemia and cyanosis but would not address hypoventilation. For those who are asymptomatic, it is important to remember that they are at risk for respiratory decompensation with stress, infections, or when undergoing procedures requiring sedation or anesthesia. CCHS patients lack the perception of dyspnea and do not manifest respiratory distress; thus, oxygen saturation monitoring with pulse oximetry should be a part of their monitoring, even though they appear nondistressed. Similarly, $\mathrm{CO}_{2}$ should be monitored (end tidal or transcutaneous), because these patients do not increase their minute ventilation even with significant hypercapnia. ${ }^{1,11,12}$

\section{Modes of ventilatory support}

Since CCHS patients generally have minimal lung disease, different modalities are available for ventilatory support. These include 1) positive pressure ventilation via tracheostomy, ${ }^{1,11,12,90}$ 2) noninvasive positive pressure ventilation (NPPV), ${ }^{11,12,91-96}$ and 3) diaphragm pacing (DP). ${ }^{1,11,12,77,97,98}$ Negative pressure ventilation ${ }^{99}$ had been used in the past, but these ventilators are not easily portable, thus limiting its current use. At our center, patients' previously utilizing this technique has been transitioned to NPPV. There is no consensus on the choice of ventilatory support. However, it is crucial for the mode of ventilation to be individualized to meet patient's needs, goals of treatment, and quality of life. At our center, we perform annual overnight polysomnographies to adjust ventilator settings, regardless of mode, to achieve target $\mathrm{PetCO}_{2} \sim 35 \mathrm{mmHg}$ and $\mathrm{SpO}_{2} \geq 95 \%$. In our experience, patients ventilated to meet these targets have more reserve for acute respiratory infections or changes in pulmonary mechanics and are less likely to develop pulmonary hypertension., ${ }^{4,11,12}$

\section{Portable positive pressure ventilator via tracheostomy}

This is the most common form of ventilatory support in CCHS patients. ${ }^{1,6,14,90}$ It is particularly recommended in infants and younger children for several reasons. CCHS infants and younger children have longer sleep periods therefore require more hours of being on ventilatory support per day. In this age group, the components of the respiratory system are still unstable, thus minor respiratory infections may result in significant respiratory depression with complete apneas during both sleep and wakefulness. To achieve the target $\mathrm{SpO}_{2}$ and $\mathrm{PetCO}_{2}$, we recommend the pressure control/assist control mode. We also prefer a relatively smaller uncuffed tracheostomy tube to allow a leak to facilitate speaking and prevent pressure on the airway and development of tracheomalacia. ${ }^{4,11,12}$

\section{Noninvasive positive pressure ventilation}

CCHS patients can be ventilated by noninvasive positive pressure ventilation via mask (nasal or face) or nasal prongs using bilevel positive airway pressure ${ }^{1,91-93}$ or average volume assured pressure support ventilation mode. ${ }^{94,96}$ Continuous positive airway pressure (CPAP) should not be used in CCHS patients as they do not spontaneously increase their breathing frequency in response to hypercapnia or hypoxemia. Ideal candidates for NPPV are stable older children who require ventilatory support only during sleep..$^{1,12}$ Although there are reports of younger children ventilated solely noninvasively, ${ }^{93,95,100}$ the American Thoracic Society recommends noninvasive ventilation in older stable patients. ${ }^{1}$ Because CCHS patients do not increase their respiratory rate or tidal breaths with hypoxemia or hypercapnia, only spontaneous/ timed or timed mode with mandatory rate can guarantee breath delivery. ${ }^{11,12,91}$ Similar to CPAP, spontaneous mode is not recommended. At our center, we ventilate our patients using the timed mode only, with pressures adjusted to deliver inspiratory positive airway pressure (IPAP) and expiratory positive airway pressure (EPAP) difference that is adequate to provide optimal tidal volume. ${ }^{11,12}$ Long-term use of noninvasive ventilation by nasal mask can be associated with midface hypoplasia and dental malocclusion. Therefore, patients must alternate different interfaces and must be monitored with consideration for referral to a craniofacial team for the monitoring of facial growth as well as dental malocclusion. ${ }^{1}$

\section{DP}

DP is an attractive treatment option for CCHS patients because it can provide daytime ventilatory support without being tethered to the home mechanical ventilator for those who are 24-hour ventilator dependent. It can be the sole ventilatory support for those who are only ventilator dependent during sleep, possibly permitting tracheal decannulation. ${ }^{1,77,98}$ 
With DP, the child uses her own diaphragm as the respiratory pump. A DP system involves the following four components: 1) monopolar electrodes that are surgically implanted bilaterally on the phrenic nerves, 2) receivers that are surgically implanted on the abdomen or chest bilaterally, 3) antennae that are placed over the receivers, and 4) an external battery operated portable transmitter that generates electrical energy similar to radio frequency. The electrical energy generated by the external transmitter is transmitted via external antennae that are placed over the receivers. The receivers then convert the energy to electrical currents that are then conducted to the phrenic nerve, stimulating contraction of the diaphragms. ${ }^{1,98}$

The ideal candidate for DP should have normal diaphragm function, intact phrenic nerve, little or no lung disease, and healthy weight. Overweight and obese patients are not ideal candidates for successful DP because the high amount of adipose tissue increases the distance between the antennae and receivers of the diaphragm pacers, resulting in an increased variability in the signal inputs to the receiver., ${ }^{1,77,98}$

At our center, diaphragm pacer electrodes are surgically implanted on the phrenic nerves thoracoscopically. ${ }^{101,102}$ After surgery, the diaphragm pacers are not used immediately; as a result, patients' go back on their presurgery mode of ventilatory support. We wait $6-8$ weeks to initiate pacing in order to allow healing. We begin pacing for $1-11 / 2$ hours and gradually increase time on pacers by $30-60$ minutes each week to train the diaphragms and prevent fatigue. ${ }^{11,12,98}$ We believe that the phrenic nerve electrodes stimulate those fibers, which happen to touch the electrodes by chance, and that those fibers are often not the same fibers that are stimulated during spontaneous breathing. Second, the electrical impulse profile of the diaphragm pacers may be different from natural phrenic nerve impulses. For these two reasons, training the diaphragm is necessary to accept longer periods of pacing without fatigue. It takes an average of 6.6 months to establish full DP. ${ }^{77}$

DP permits tracheostomy decannulation in stable older CCHS patients who require ventilatory support only during sleep. To be considered for DP without tracheostomy, a CCHS patient should meet the following requirements: 1) ventilator dependence only during sleep, 2) not requiring daytime naps, 3) stable medical course with infrequent hospitalizations, 4) not requiring full-time ventilatory support during acute respiratory illnesses, and 5) acceptance that DP is not a secure method of ventilation and intubations maybe necessary for serious illnesses..$^{77} \mathrm{~A}$ disadvantage of DP without tracheostomy is the risk of obstructive sleep apnea, which can occur due to the diaphragm contraction without concomitant upper airway muscle contraction. ${ }^{1,77,103}$ Wang et al ${ }^{103}$ reported that obstructive sleep apnea (OSA) if present during DP without tracheostomy, it can be alleviated by decreasing the DP amplitude settings to decrease the force of inspiration with each diaphragmatic contraction.

Because of the risk of diaphragm fatigue, we recommend that DP only be used for up to 14-16 hours a day.,11,12,98 Therefore, during an acute illness, a patient must have an alternative form of ventilatory support when additional time is required on assisted ventilation beyond 14-16 hours is necessary. In these circumstances, a patient can be connected back to the home ventilator if the tracheostomy tube is still in place. If a patient has been decannulated, ventilatory support by NPPV is provided.

\section{Genetic counseling for CCHS}

$P H O X 2 B$ gene mutation in CCHS has an autosomal pattern of inheritance $e^{1,13,104}$ with variable penetrance. Although most cases occur de novo, it is necessary to test the parents of the affected patient even if they do not report symptoms. Bachetti et $\mathrm{al}^{69}$ re-examined parents of CCHS patients without any mutation detected via PHOX2B sequencing test, by using an improved molecular protocol, "FAM" method, and found low levels of mosaicism and increased recurrence risk of 25\%. The short sized PARMs (ie, 20/24 and 20/25) and some NPARMs have incomplete penetrance, and therefore, affected individuals may be asymptomatic until they are older or experience a trigger that puts them in respiratory compromise.

Genetic counseling is imperative for individuals diagnosed with CCHS and their families as there is a $50 \%$ chance of recurrence with each child. Thus, if a parent is affected, there is also a $50 \%$ risk of CCHS to the patient's siblings.

Prenatal testing is recommended in all mothers with CCHS. ${ }^{1,105}$ Prenatal testing will allow parents' optimal information with which to make an informed decision and aid the obstetrician and the pregnant mother plan for smooth delivery. Rajendran et a ${ }^{105}$ reported a case of CCHS diagnosed in utero at 18 weeks gestation by $P H O X 2 B$ gene analysis in fetal amniocytes. The fetus was not noted to initiate breathing or tachypnea in response to modest hypercapnia resulting from transient maternal breath holding. At birth, the infant was unable to establish adequate spontaneous breathing despite normal Apgar scores and thus was subsequently intubated and mechanically ventilated at the age of 1 hour. ${ }^{105}$ This case underscores the importance of prenatal testing. Knowledge of the anticipated infants' status prepares the medical and 
nursing teams to optimally plan for the infant's care in the delivery room and neonatal intensive care unit. ${ }^{1}$

\section{Conclusion}

In the past 50 years, there has been a tremendous advancement in our knowledge of CCHS. Although CCHS is a rare disease, the discovery of the disease defining gene, $P H O X 2 B$, has increased early identification of CCHS patients, defined their clinical presentations, and brought new insights in the ability to provide optimal care tailored to their needs. The PHOX2B gene mutation analysis not only confirms the diagnosis of CCHS but also aids in predicting the outcome and management of CCHS. The capacity for early identification of CCHS via genetic testing methods allows the clinicians to provide early intervention to prevent morbidity and mortality and improve the patient's and family's quality of life.

\section{Disclosure}

The authors report no conflicts of interest in this work.

\section{References}

1. Weese-Mayer DE, Berry-Kravis EM, Ceccherini I, Keens TG, Loghmanee DA, Trang H. An official ATS clinical policy statement: Congenital central hypoventilation syndrome: genetic basis, diagnosis, and management. Am J Respir Crit Care Med. 2010;181(6):626-644.

2. Fleming PJ, Cade D, Bryan MH, Bryan AC. Congenital central hypoventilation and sleep state. Pediatrics. 1980;66(3):425-428.

3. Huang J, Colrain IM, Panitch HB, et al. Effect of sleep stage on breathing in children with central hypoventilation. J Appl Physiol. 2008;105(1):44-53.

4. Chen ML, Keens TG. Congenital central hypoventilation syndrome: not just another rare disorder. Paediatr Respir Rev. 2004;5(3):182-189.

5. Weese-Mayer DE, Shannon DC, Keens TG, Silvestri JM. Idiopathic congenital central hypoventilation syndrome: diagnosis and management. American Thoracic Society. Am J Respir Crit Care Med. 1999;160(1):368-373.

6. Trang H, Dehan M, Beaufils F, Zaccaria I, Amiel J, Gaultier C. The French Congenital Central Hypoventilation Syndrome Registry: general data, phenotype, and genotype. Chest. 2005;127(1):72-79.

7. Shimokaze T, Sasaki A, Meguro T, et al. Genotype-phenotype relationship in Japanese patients with congenital central hypoventilation syndrome. J Hum Genet. 2015;60(9):473-477.

8. Amiel J, Laudier B, Attié-Bitach T, et al. Polyalanine expansion and frameshift mutations of the paired-like homeobox gene PHOX2B in congenital central hypoventilation syndrome. Nat Genet. 2003;33(4):459-461.

9. Weese-Mayer DE, Berry-Kravis EM, Zhou L, et al. Idiopathic congenital central hypoventilation syndrome: Analysis of genes pertinent to early autonomic nervous system embryologic development and identification of mutations in PHOX2b. Am J Med Genet. 2003;123A(3):267-278.

10. Hasegawa H, Kawasaki K, Inoue H, Umehara M, Takase M. Japanese Society of Pediatric Pulmonology Working Group (JSPPWG). Epidemiologic survey of patients with congenital central hypoventilation syndrome in Japan. Pediatr Int. 2012;54(1):123-126.

11. Kasi A, Perez I, Kun S, Keens T. Congenital central hypoventilation syndrome: Diagnostic and management challenges. Pediatr Heal Med Ther. 2016;7:99-107.
12. Maloney MA, Kun SS, Keens TG, Perez IA. Congenital central hypoventilation syndrome: diagnosis and management. Expert Rev Respir Med. 2018;12(4):283-292.

13. Kasi AS, Jurgensen TJ, Yen S, et al. Three-Generation Family With Congenital Central Hypoventilation Syndrome and Novel PHOX2B Gene Non-Polyalanine Repeat Mutation. J Clin Sleep Med. 2017;13(07):925-927.

14. Vanderlaan M, Holbrook CR, Wang M, Tuell A, Gozal D. Epidemiologic survey of 196 patients with congenital central hypoventilation syndrome. Pediatr Pulmonol. 2004;37(3):217-229.

15. Magalhães J, Madureira N, Medeiros R, et al. Late-onset congenital central hypoventilation syndrome and a rare PHOX2B gene mutation. Sleep Breath. 2015;19(1):55-60.

16. Doherty LS, Kiely JL, Deegan PC, et al. Late-onset central hypoventilation syndrome: a family genetic study. Eur Respir J. 2007;29(2):312-316.

17. Barratt S, Kendrick AH, Buchanan F, Whittle AT. Central hypoventilation with PHOX2B expansion mutation presenting in adulthood. Thorax. 2007;62(10):919-920.

18. Trang H, Laudier B, Trochet D, et al. PHOX2B gene mutation in a patient with late-onset central hypoventilation. Pediatr Pulmonol. 2004;38(4):349-351.

19. Mahmoud M, Bryan Y, Gunter J, Kreeger RN, Sadhasivam S. Anesthetic implications of undiagnosed late onset central hypoventilation syndrome in a child: from elective tonsillectomy to tracheostomy. Pediatric Anesthesia. 2007;17(10):1001-1005.

20. Mahfouz AK, Rashid M, Khan MS, Reddy P. Late onset congenital central hypoventilation syndrome after exposure to general anesthesia. Can J Anaesth. 2011;58(12):1105-1109.

21. Antic NA, Malow BA, Lange N, et al. PHOX2B mutation-confirmed congenital central hypoventilation syndrome: Presentation in adulthood. Am J Respir Crit Care Med. 2006;174(8):923-927.

22. Repetto GM, Corrales RJ, Abara SG, et al. Later-onset congenital central hypoventilation syndrome due to a heterozygous 24-polyalanine repeat expansion mutation in the PHOX2B gene. Acta Paediatr. 2009;98(1):192-195.

23. Paton JY, Swaminathan S, Sargent CW, Keens TG. Hypoxic and hypercapnic ventilatory responses in awake children with congenital central hypoventilation syndrome. Am Rev Respir Dis. 1989;140(2):368-372.

24. Shea SA, Andres LP, Paydarfar D, Banzett RB, Shannon DC. Effect of mental activity on breathing in congenital central hypoventilation syndrome. Respir Physiol. 1993;94(3):251-263.

25. Diedrich A, Malow BA, Antic NA, et al. Vagal and sympathetic heart rate and blood pressure control in adult onset PHOX2B mutationconfirmed congenital central hypoventilation syndrome. Clin Auton Res. 2007;17(3):177-185.

26. Rita Azeredo Bittencourt L, Pedrazzoli M, Yagihara F, et al. Lateonset, insidious course and invasive treatment of congenital central hypoventilation syndrome in a case with the Phox2B mutation: case report. Sleep Breathe. 2012;16:951-955.

27. Antic N, Mcevoy RD. Primary alveolar hypoventilation and response to the respiratory stimulant almitrine. Intern Med J. 2002;32(12):622-624.

28. F-G MR, Manna S, Durward A. Cor pulmonale due to congenital central hypoventilation syndrome presenting in adolescence. Pediatr Crit Care Med. 2009;10(4):e41-2 1p.

29. Chuen-Im P, Marwan S, Carter J, Kemp J, Rivera-Spoljaric K. Heterozygous 24-polyalanine repeats in the $P H O X 2 B$ gene with different manifestations across three generations. Pediatr Pulmonol. 2014;49(2):E13-E16.

30. Swaminathan S, Gilsanz V, Atkinson J, Thomas GK, Keens TG. Congenital central hypoventilation syndrome associated with multiple ganglioneuromas. Chest. 1989;96(2):423-424.

31. Jennings LJ, Yu M, Rand CM, et al. Variable human phenotype associated with novel deletions of the PHOX2B gene. Pediatr Pulmonol. 2012;47(2):153-161. 
32. Trochet D, O’Brien LM, Gozal D, et al. PHOX2B genotype allows for prediction of tumor risk in congenital central hypoventilation syndrome. Am J Hum Genet. 2005;76(3):421-426.

33. Faure C, Viarme F, Cargill G, Navarro J, Gaultier C, Trang H. Abnormal esophageal motility in children with congenital central hypoventilation syndrome. Gastroenterology. 2002;122(5):1258-1263.

34. Rohrer T, Trachsel D, Engelcke G, Hammer J, Hammer J. Congenital central hypoventilation syndrome associated with Hirschsprung's disease and neuroblastoma: case of multiple neurocristopathies. Pediatr Pulmonol. 2002;33(1):71-76.

35. Woo MS, Woo MA, Gozal D, Jansen MT, Keens TG, Harper RM. Heart rate variability in congenital central hypoventilation syndrome. Pediatr Res. 1992;31(3):291-296.

36. Silvestri JM, Hanna BD, Volgman AS, Jones PJ, Barnes SD, WeeseMayer DE. Cardiac rhythm disturbances among children with idiopathic congenital central hypoventilation syndrome. Pediatr Pulmonol. 2000;29(5):351-358.

37. Gronli JO, Santucci BA, Leurgans SE, Berry-Kravis EM, WeeseMayer DE. Congenital central hypoventilation syndrome:PHOX2B genotype determines risk for sudden death. Pediatr Pulmonol. 2008;43(1):77-86.

38. Trang H, Girard A, Laude D, Elghozi JL. Short-term blood pressure and heart rate variability in congenital central hypoventilation syndrome (Ondine's curse). Clin Sci. 2005;108(3):225-230.

39. Trang H, Boureghda S, Denjoy I, Alia M, Kabaker M. 24-hour BP in children with congenital central hypoventilation syndrome. Chest. 2003;124(4):1393-1399.

40. Goldberg DS, Ludwig IH. Congenital central hypoventilation syndrome: ocular findings in 37 children. J Pediatr Ophthalmol Strabismus. 1996;33(3):175-180.

41. Basu AP, Bellis P, Whittaker RG, Mckean MC, Devlin AM. Teaching NeuroImages: Alternating ptosis and Marcus Gunn jaw-winking phenomenon with PHOX2B mutation. Neurology. 2012;79(17):e153.

42. Patwari PP, Stewart TM, Rand CM, et al. Pupillometry in congenital central hypoventilation syndrome (CCHS): quantitative evidence of autonomic nervous system dysregulation. Pediatr Res. 2012;71(3):280-285.

43. Boulanger-Scemama E, Fardeau C, Straus C, et al. Ophthalmologic impairment during adulthood in central congenital hypoventilation syndrome: a longitudinal cohort analysis of nine patients. Ophthalmic Genet. 2014;35(4):229-234.

44. Hennewig U, Hadzik B, Vogel M, et al. Congenital central hypoventilation syndrome with hyperinsulinism in a preterm infant. J Hum Genet. 2008;53(6):573-577.

45. Farina MI, Scarani R, Po' C, Agosto C, Ottonello G, Benini F. Congenital central hypoventilation syndrome and hypoglycaemia. Acta Paediatr. 2012;101(2):e92-e96.

46. Marics G, Amiel J, Vatai B, Lódi C, Mikos B, Tóth-Heyn P. Autonomic dysfunction of glucose homoeostasis in congenital central hypoventilation syndrome. Acta Paediatr. 2013;102(4):e178-e180.

47. Gelwane G, Trang H, Carel J-C, Dauger S, Léger J. Intermittent hyperglycemia due to autonomic nervous system dysfunction: a new feature in patients with congenital central hypoventilation syndrome. J Pediatr. 2013;162(1):171-176.

48. Hopkins E, Stark J, Mosquera RA. Central Congenital Hypoventilation Syndrome associated with hypoglycemia and seizure. Respir Med Case Rep. 2017;20:75-76.

49. Saiyed R, Rand CM, Carroll MS, et al. Congenital central hypoventilation syndrome (CCHS): Circadian temperature variation. Pediatr Pulmonol. 2016;51(3):300-307.

50. Weese-Mayer DE, Rand CM, Zhou A, Carroll MS, Hunt CE. Congenital central hypoventilation syndrome: a bedside-to-bench success story for advancing early diagnosis and treatment and improved survival and quality of life. Pediatr Res. 2017;81(1-2):192-201.

51. Pattyn A, Morin X, Cremer H, Goridis C, Brunet J-F. The homeobox gene Phox $2 b$ is essential for the development of autonomic neural crest derivatives. Nature. 1999;399(6734):366-370.
52. Pattyn A, Morin X, Cremer H, Goridis C, Brunet J-F. Expression and interactions of the two closely related homeobox genes Phox $2 \mathrm{a}$ and Phox $2 \mathrm{~b}$ during neurogenesis. Development. 1997;1249374403(20):4065-4075.

53. Marcus CL, Bautista DB, Amihyia A, Ward SL, Keens TG. Hypercapneic arousal responses in children with congenital central hypoventilation syndrome. Pediatrics. 1991;88(5):993-998.

54. Gozal D, Marcus CL, Shoseyov D, Keens TG. Peripheral chemoreceptor function in children with the congenital central hypoventilation syndrome. J Appl Physiol. 1993;74(1):379-387.

55. Stornetta RL, Moreira TS, Takakura AC, et al. Expression of Phox $2 b$ by brainstem neurons involved in chemosensory integration in the adult rat. $J$ Neurosci. 2006;26(40):10305-10314.

56. Takakura AC, Barna BF, Cruz JC, Colombari E, Moreira TS. Phox2bexpressing retrotrapezoid neurons and the integration of central and peripheral chemosensory control of breathing in conscious rats. Exp Physiol. 2014;99(3):571-585.

57. Dauger S. Phox $2 \mathrm{~b}$ controls the development of peripheral chemoreceptors and afferent visceral pathways. Development 2003;130(26):6635-6642.

58. Moreira TS, Takakura AC, Czeisler C, Otero JJ. Respiratory and autonomic dysfunction in congenital central hypoventilation syndrome. $J$ Neurophysiol. 2016;116(2):742-752.

59. Guyenet PG, Stornetta RL, Abbott SBG, Depuy SD, Kanbar R. The retrotrapezoid nucleus and breathing. In: Advances in Experimental Medicine and Biology. Vol. 2012;758:115-122.

60. Dubreuil V, Barhanin J, Goridis C, Brunet J-F. Breathing with Phox2b. Philosophical Transactions of the Royal Society B: Biological Sciences. 2009:364(1529):2477-2483.

61. Dubreuil V, Ramanantsoa N, Trochet D, et al. A human mutation in Phox $2 \mathrm{~b}$ causes lack of $\mathrm{CO} 2$ chemosensitivity, fatal central apnea, and specific loss of parafacial neurons. Proc Natl Acad Sci U S A. 2008;105(3):1067-1072.

62. Rudzinski E, Kapur RP. PHOX2B immunolocalization of the candidate human retrotrapezoid nucleus. Pediatr Dev Pathol. 2010;13(4):291-299.

63. Pattyn A, Goridis C, Brunet JF. Specification of the central noradrenergic phenotype by the homeobox gene Phox2b. Mol Cell Neurosci. 2000;15(3):235-243.

64. Nobuta H, Cilio MR, Danhaive O, et al. Dysregulation of locus coeruleus development in congenital central hypoventilation syndrome. Acta Neuropathol. 2015;130(2):171-183.

65. Tomycz ND, Haynes RL, Schmidt EF, Ackerson K, Kinney HC. Novel neuropathologic findings in the Haddad syndrome. Acta Neuropathol. 2010;119(2):261-269.

66. Ogren JA, Macey PM, Kumar R, Woo MA, Harper RM. Central autonomic regulation in congenital central hypoventilation syndrome. Neuroscience. 2010;167(4):1249-1256.

67. Weese-Mayer DE, Marazita ML, Rand CM, Berry-Kravis EM Congenital Central Hypoventilation Syndrome. Seattle: University of Washington; 2014. Available from: http://www.ncbi.nlm.nih.gov/ pubmed/20301600. Accessed July 25, 2018.

68. Jennings LJ, Yu M, Zhou L, Rand CM, Berry-Kravis EM, WeeseMayer DE. Comparison of PHOX2B testing methods in the diagnosis of congenital central hypoventilation syndrome and mosaic carriers. Diagn Mol Pathol. 2010;19(4):224-231.

69. Bachetti T, Parodi S, di Duca M, Santamaria G, Ravazzolo R, Ceccherini I. Low amounts of PHOX2B expanded alleles in asymptomatic parents suggest unsuspected recurrence risk in congenital central hypoventilation syndrome. J Mol Med. 2011;89(5):505-513.

70. Barrett PM, Komatireddy R, Haaser S, et al. Comparison of 24-hour Holter Monitoring with 14-day Novel Adhesive Patch Electrocardiographic Monitoring. Am J Med. 2014;127(1):95.e11-95.e17-95.

71. Walsh JA, Topol EJ, Steinhubl SR. Novel Wireless Devices for Cardiac Monitoring. Circulation. 2014;130(7):573-581.

72. Zelko FA, Nelson MN, Leurgans SE, Berry-Kravis EM, Weese-Mayer DE. Congenital central hypoventilation syndrome: Neurocognitive functioning in school age children. Pediatr Pulmonol. 2010;45(1):92-98. 
73. Charnay AJ, Antisdel-Lomaglio JE, Zelko FA, et al. Congenital Central Hypoventilation Syndrome: Neurocognition Already Reduced in Preschool-Age Children. Chest. 2015.

74. Silvestri JM, Weese-Mayer DE, Nelson MN. Neuropsychologic abnormalities in children with congenital central hypoventilation syndrome. J Pediatr. 1992;120(3):388-393.

75. Zelko FA, Stewart TM, Brogadir CD, Rand CM, Weese-Mayer DE. Congenital central hypoventilation syndrome: Broader cognitive deficits revealed by parent controls. Pediatr Pulmonol. 2018;53(4):492-497.

76. Marcus CL, Jansen MT, Poulsen MK, et al. Medical and psychosocial outcome of children with congenital central hypoventilation syndrome. J Pediatr. 1991;119(6):888-895.

77. Diep B, Wang A, Kun S, et al. Diaphragm Pacing without Tracheostomy in Congenital Central Hypoventilation Syndrome Patients. Respiration. 2015;89(6):534-538.

78. Matera Iet al. PHOX2B mutations and polyalanine expansions correlate with the severity of the respiratory phenotype and associated symptoms in both congenital and late onset Central Hypoventilation syndrome. J Med Genet. 2004;41(5):373-380.

79. Trochet D, Hong SJ, Lim JK, et al. Molecular consequences of PHOX2B missense, frameshift and alanine expansion mutations leading to autonomic dysfunction. Hum Mol Genet. 2005;14(23):3697-3708.

80. Bachetti T, Matera I, Borghini S, Duca MD, Ravazzolo R, Ceccherini I. Distinct pathogenetic mechanisms for PHOX2B associated polyalanine expansions and frameshift mutations in congenital central hypoventilation syndrome. Hum Mol Genet. 2005;14(13):1815-1824.

81. di Lascio S, Bachetti T, Saba E, Ceccherini I, Benfante R, Fornasari D. Transcriptional dysregulation and impairment of PHOX2B autoregulatory mechanism induced by polyalanine expansion mutations associated with congenital central hypoventilation syndrome. Neurobiol Dis. 2013;50:187-200.

82. H-T W, Y-N S, Hung C-C, Hsieh W-S, K-J W. Interaction between PHOX2B and CREBBP mediates synergistic activation: mechanistic implications of PHOX2B mutants. Hum Mutat. 2009;30(4):655-660.

83. Low KJ, Turnbull AR, Smith KR, et al. A case of congenital central hypoventilation syndrome in a three-generation family with non-polyalanine repeat PHOX2B mutation. Pediatr Pulmonol. 2014;49(10):E140-E143.

84. Cain JT, Kim DI, Quast M, et al. Nonsense pathogenic variants in exon 1 of $P H O X 2 B$ lead to translational reinitiation in congenital central hypoventilation syndrome. Am J Med Genet A. 2017;173(5):1200-1207.

85. Lombardo RC, Kramer E, Cnota JF, Sawnani H, Hopkin RJ. Variable phenotype in a novel mutation in PHOX2B. Am J Med Genet A. 2017;173(6):1705-1709.

86. di Lascio S, Benfante R, di Zanni E, et al. Structural and functional differences in $P H O X 2 B$ frameshift mutations underlie isolated or syndromic congenital central hypoventilation syndrome. Hum Mutat. 2018;39(2):219-236.

87. Berry-Kravis EM, Zhou L, Rand CM, Weese-Mayer DE. Congenital central hypoventilation syndrome: $\mathrm{PHOX} 2 \mathrm{~B}$ mutations and phenotype. Am J Respir Crit Care Med. 2006;174(10):1139-1144.

88. Kwon M-J, Lee G-H, Lee M-K, et al. PHOX2B mutations in patients with Ondine-Hirschsprung disease and a review of the literature. Eur J Pediatr. 2011;170(10):1267-1271.
89. Trang H, Brunet J-F, Rohrer H, et al. Proceedings of the fourth international conference on central hypoventilation. Orphanet J Rare Dis. 2014;9(1):194.

90. Beckerman R. Home positive pressure ventilation in congenital central hypoventilation syndrome: more than twenty years of experience. Pediatr Pulmonol. 1997;23:154-155.

91. Perez IA, Keens TG, Davidson Ward SL. Noninvasive positive pressure ventilation in the treatment of hypoventilation in children. Sleep Med Clin. 2010;5(3):471-484.

92. Kerbl R, Litscher H, Grubbauer HM, et al. Congenital central hypoventilation syndrome (Ondine's curse syndrome) in two siblings: Delayed diagnosis and successful noninvasive treatment. Eur J Pediatr. 1996;155(11):977-980.

93. Migliori C, Cavazza A, Motta M, Bottino R, Chirico G. Early use of Nasal-BiPAP in two infants with Congenital Central Hypoventilation syndrome. Acta Paediatr. 2003;92(7):823-826.

94. Vagiakis E, Koutsourelakis I, Perraki E, et al. Average volume-assured pressure support in a 16-year-old girl with congenital central hypoventilation syndrome. J Clin Sleep Med. 2010;6(6):609-612.

95. Kam K, Bjornson C, Mitchell I. Congenital central hypoventilation syndrome; Safety of early transition to non-invasive ventilation. Pediatr Pulmonol. 2014;49(4):410-413.

96. Khayat A, Medin D, Syed F, et al. Intelligent volume-assured pressured support (iVAPS) for the treatment of congenital central hypoventilation syndrome. Sleep Breath. 2017;21(2):513-519.

97. Weese-Mayer DE, Hunt CE, Brouillette RT, Silvestri JM. Diaphragm pacing in infants and children. J Pediatr. 1992;120(1):1-8.

98. Chen ML, Tablizo MA, Kun S, Keens TG. Diaphragm pacers as a treatment for congenital central hypoventilation syndrome. Expert Rev Med Devices. 2005;2(5):577-585.

99. Hartmann H, Jawad MH, Noyes J, Samuels MP, Southall DP. Negative extrathoracic pressure ventilation in central hypoventilation syndrome. Arch Dis Child. 1994;70(5):418-423.

100. Tibballs J, Henning RD. Noninvasive ventilatory strategies in the management of a newborn infant and three children with congenital central hypoventilation syndrome. Pediatr Pulmonol. 2003;36(6):544-548.

101. Shaul DB, Danielson PD, Mccomb JG, Keens TG. Thoracoscopic placement of phrenic nerve electrodes for diaphragmatic pacing in children. J Pediatr Surg. 2002;37(7):974-978.

102. Nicholson KJ, Nosanov LB, Bowen KA, et al. Thoracoscopic placement of phrenic nerve pacers for diaphragm pacing in congenital central hypoventilation syndrome. J Pediatr Surg. 2015;50(1):78-81.

103. Wang A, Kun S, Diep B, Davidson Ward SL, Keens TG, Perez IA. Obstructive Sleep Apnea in Patients With Congenital Central Hypoventilation Syndrome Ventilated by Diaphragm Pacing Without Tracheostomy. J Clin Sleep Med. 2018;14(2):261-264.

104. Sritippayawan S, Hamutcu R, Kun SS, Ner Z, Ponce M, Keens TG. Mother-daughter transmission of congenital central hypoventilation syndrome. Am J Respir Crit Care Med. 2002;166(3):367-369.

105. Rajendran GP, Kessler MS, Manning FA. Congenital Central Hypoventilation syndrome (Ondine's curse): prenatal diagnosis and fetal breathing characteristics. J Perinatol. 2009;29(10):712-713.
The Application of Clinical Genetics

\section{Publish your work in this journal}

The Application of Clinical Genetics is an international, peer-reviewed open access journal that welcomes laboratory and clinical findings in the field of human genetics. Specific topics include: Population genetics; Functional genetics; Natural history of genetic disease; Management of genetic disease; Mechanisms of genetic disease; Counselling and ethical

\section{Dovepress}

issues; Animal models; Pharmacogenetics; Prenatal diagnosis; Dysmorphology. The manuscript management system is completely online and includes a very quick and fair peer-review system, which is all easy to use. Visit http://www.dovepress.com/testimonials.php to read real quotes from published authors. 